\title{
National Priorities for High-quality Rheumatology Transition Care for Youth in Canada
}

\author{
Cheryl Barnabe ${ }^{1}$ (D), Kelsey Chomistek ${ }^{2}$ (D), Nadia Luca ${ }^{3}$ (D), Glen Hazlewood ${ }^{4}$ (D), Claire E.H. Barber ${ }^{5}$ (D), \\ Amanda Steiman ${ }^{6}$, and Elizabeth Stringer ${ }^{7}$
}

\begin{abstract}
Objective. To conduct a needs assessment and environmental scan to support optimal transition from pediatric to adult rheumatology care in Canada.

Methods. This initiative involved 3 phases: (1) a survey-based needs assessment of adult and pediatric rheumatologist members of the Canadian Rheumatology Association to identify perceived infrastructure, educational needs, and national resources to support transition care; (2) an environmental scan, through semistructured interviews, of existing rheumatology transition service care models and challenges in care delivery; and (3) a focus group to prioritize national activities.

Results. The needs assessment survey was completed by 65 members, with $66 \%$ agreeing that a national approach to transition care was needed. Semistructured interviews reflecting activities at 9 transition care sites were conducted, and they identified candidate models of care, including direct transfer, progressive transfer, and shared care models. Challenges and needs experienced in these care models reflected resource and infrastructure needs, poor availability of mechanisms to support parents and youth through the transition process, and the need for evaluation to support quality improvement. The focus group and prioritization activity was attended by 26 participants, with each having the ability to cast 3 votes. "Supporting patient education for transition to adult rheumatology health care system" ( $\mathrm{n}=17$ votes) and "advocacy activities to access allied health support, including funding" ( $\mathrm{n}=10$ votes) emerged as the top priorities for national initiatives.

Conclusion. We have identified priorities in education and advocacy for advancing transition care in Canada that require participation of pediatric and adult rheumatology providers, patients, and arthritis stakeholders in the interest of advancing transition care outcomes.
\end{abstract}

Key Indexing Terms: needs assessment, quality of health care, rheumatology, transition to adult care

Adolescents with chronic rheumatic diseases require a transfer of medical care from the pediatric to adult healthcare systems. While "transfer" is typically regarded as a single point in time when an adult provider assumes care from the pediatric provider, "transition" is a process that begins well before the actual transfer and continues into young adulthood. Within transition activities, youth and care teams go through progressive planning, as well as knowledge and skill development toward independent management of chronic conditions ${ }^{1}$. Transition occurs in parallel with normal adolescent development, which includes changes in cognition from concrete to abstract thinking, moving toward increasing autonomy, identification of peer groups, and emotional, physical, and sexual development. Key goals for transition and transfer are to optimize health outcomes and facilitate each young person's attainment of their potential as they move into adulthood ${ }^{2}$.
This study was supported in kind by the Canadian Rheumatology

Association's Pediatrics and Quality Care Committees, and through the Canada Research Chair in Rheumatoid Arthritis and Autoimmune Diseases beld by C. Barnabe.

${ }^{1}$ C. Barnabe, MD, MSc, Associate Professor, Departments of Medicine and Community Health Sciences, Cumming School of Medicine, University of Calgary, Calgary, Alberta, and Past-Chair, Quality Care Committee, Canadian Rheumatology Association; ${ }^{2} \mathrm{~K}$. Chomistek, BSc, Masters of Science student, Faculty of Graduate Studies, University of Calgary, Calgary, Alberta; ${ }^{3}$ N. Luca, MD, MSc, Clinical Assistant Professor in the Department of Pediatrics, Cumming School of Medicine, University of Calgary, Calgary, Alberta, and Executive, Pediatrics Committee, Canadian Rheumatology Association; ${ }^{4}$ G. Hazlewood, MD, PhD, Assistant Professor, Departments of Medicine and Community Health Sciences, Cumming School of Medicine, University of Calgary, Calgary, Alberta, and Member, Quality Care Committee, Canadian Rheumatology Association; ${ }^{5}$ C.E. Barber, MD,
PhD, Assistant Professor, Departments of Medicine and Community Health Sciences, Cumming School of Medicine, University of Calgary, Calgary, Alberta, and Member, Quality Care Committee, Canadian Rheumatology Association; ${ }^{6}$ A. Steiman, MD, MSc, Assistant Professor, Department of Medicine, Faculty of Medicine, University of Toronto, Toronto, Ontario, and Chair, Quality Care Committee, Canadian Rheumatology Association; ${ }^{7}$ E. Stringer, MD, Associate Professor, Department of Pediatrics, Faculty of Medicine, Dalhousie University, Halifax, Nova Scotia, and Member, Pediatrics Committee, Canadian Rheumatology Association, Canada.

The authors have no conflicts of interest to declare.

Address correspondence to Dr. C. Barnabe, 3330 Hospital Dr NW, Calgary, ABT2N4N1, Canada.Email: ccbarnab@ucalgary.ca.

Full Release Article. For details see Reprints and Permissions at jrheum.org. Accepted for publication September 29, 2020. 
There is growing evidence for the value of transition care in rheumatology outcomes ${ }^{3}$, but most of the evidence supports transition and transfer periods as being high-risk periods for gaps in care leading to poor patient outcomes. Continuity of care is a key indicator of successful transition ${ }^{4}$, yet $25-75 \%$ of youth with juvenile idiopathic arthritis (JIA) and other rheumatic diseases have a gap in their care or are lost to follow-up during transfer to adult services ${ }^{5,6,7,8}$. This is a disturbingly high rate for conditions that require long-term treatment and have the potential for significant morbidity and mortality. Further, the transfer period occurs with an increased incidence of mental health comorbidities, emphasizing the need for continuous contact with the healthcare system ${ }^{8,9}$.

The European League Against Rheumatism (EULAR)/ Pediatric Rheumatology European Society (PReS) has published guidelines for the transition of children with juvenile-onset rheumatic diseases ${ }^{10}$. Despite increased attention to the practice of transition, barriers to providing optimal care remain, including education and exposure to high-quality transition during training ${ }^{11}$, and appropriate healthcare infrastructure and patient supports for the transition process ${ }^{3}$. In a study including both American and Canadian pediatric rheumatologists, insufficient time to provide transition services, perceived insufficient readiness and self-management skills of adolescents, fragmentation and lack of primary and specialty adult care providers, and lack of knowledge about linkages to community resources that support young adults were reported ${ }^{12}$. In a previous Canadian rheumatologist workforce survey, $25 \%$ of adult rheumatologists reported providing care in transition clinics and another $25 \%$ reported having provided care to patients $<18$ years of age, who presumably were without specific structured supports ${ }^{13}$. This evidence suggests that gaps exist in the transitional care of adolescents and young adults with rheumatic disease in Canada, yet international guidelines may not reflect context-specific factors such as health system structure or the nature of interactions between pediatric and rheumatology care providers; thus, this gap speaks to the need for individual countries to plan their uniquely needed activities ${ }^{14}$. The objective of this study was to identify national priorities to support and improve transition care initiatives.

\section{MATERIALS AND METHODS}

Phase 1: Needs assessment. We developed a survey for Canadian rheumatologists (Supplementary Data, available from the authors on request) based on 2 previous surveys conducted in the United States ${ }^{12,15}$. We sought to identify current involvement in transition care, preparation activities for providing this care, and awareness of existing transition resources. Participants were asked to identify barriers to transition care encountered in their practices, as well as perceived needs and areas of focus to be pursued. Demographic information was collected to contextualize responses. The survey was available in English and French, with a combination of close-ended responses and free-text fields. The survey was administered using QualtricsXM and distributed to adult and pediatric rheumatologists in Canada through the Canadian Rheumatology Association (CRA) email system in January 2020, with a reminder sent in February 2020. Analysis was conducted in STATA IC 16.1 (StataCorp) to generate descriptive statistics, with stratified analyses based on adult or pediatric rheumatologist practice, training in transition care, and current involvement in transition care.
Phase 2: Environmental scan of existing transition models in Canada. Environmental scans fulfill several roles in healthcare, including the examination of existing programs and services for specific populations; the assessment of community, practice, and education supports required; and the guidance of quality improvement initiatives ${ }^{16}$. Passive (collecting existing knowledge) and active (creating new knowledge) approaches are described, and analysis is descriptive in nature ${ }^{17}$. Semistructured interviews were conducted to gather information on the structure and processes of existing rheumatology transition and transfer clinics. Interview questions were based on the guidelines for structure and process of transitional care from the Canadian Association of Paediatric Health Centres (CAPHC), the Canadian Paediatrics Society (CPS), the American Academy of Pediatrics (AAP), and the EULAR/PReS standards ${ }^{1,10,18}$ (Supplementary Data, available from the authors on request). Potential interview participants were identified by the research team through several mechanisms, including rheumatologists known to be engaged in transition care provision with the assistance of the CRA Pediatrics Committee, and through the suggestions of participants completing interviews. Participants were invited by email and all interviews for consenting participants were conducted by telephone in English by 1 member of the research team (CB).

Phase 3: Focus group. A general invitation for participation at a combined in-person and online focus group prior to the opening of the CRA Annual Scientific Meeting in February 2020 was distributed by email by the organization. Individualized invitations were sent by the investigators to rheumatologists and allied health professionals with a known interest in transition care, and to patient representatives from the juvenile rheumatic disease community. The focus group was facilitated by a research team member who has qualitative and quantitative research experience and who is a national representative and peer group leader for patients with juvenile rheumatic diseases (KC). A Web-based meeting platform and teleconference lines facilitated remote participation, as the facilitator would interact with both in-person and remote participants. During the focus group, results of the needs assessment and environmental scan were shared with participants, and the list of candidate priorities generated from these sources for national activities were presented. Discussion on the candidate priority areas followed to clarify domains and add other candidate items. Participants were then asked to participate in a Dotmocracy voting process ${ }^{19}$, with each receiving 3 votes to cast (either using physical "dot" stickers, or through email if attending remotely) on which priorities were of most importance to pursue at the national level. Votes were tallied to identify the top priorities, followed by group discussions on activities to complete and stakeholders to involve in future initiatives.

Ethical approval. All phases of this study were approved by the University of Calgary Conjoint Health Research Ethics Board (REB19-1979).

\section{RESULTS}

Phase 1: Needs assessment survey

1.1 Participant characteristics. A total of 36 adult rheumatologists, 25 pediatric rheumatologists, and 4 rheumatologists providing care to both population groups participated $(n=65$ of 585 CRA members, 11.1\%), with demographic characteristics presented in Table 1. Eighteen (28\%) respondents (10 pediatric, 7 adult, and 1 rheumatologist providing care to both adult and pediatric populations) were actively providing transition care in a multidisciplinary transition service. Fourteen (22\%) respondents ( 7 pediatric, 4 adult, and 3 both) had formal transition care training, acquired during medical school $(n=2)$, internal medicine or pediatric residency $(n=5)$, rheumatology residency or fellowship $(n=11)$, or through workshops $(n=5)$, conferences $(n=6)$, or a local education session $(n=4)$. 
Table 1. Needs assessment survey participant characteristics.

\begin{tabular}{|c|c|c|}
\hline Characteristics & Category Description & $\begin{array}{c}\text { Participants, } \\
\mathrm{n}=65, \%^{\mathrm{a}}\end{array}$ \\
\hline \multirow[t]{3}{*}{ Rheumatology specialty } & Adult practice & 55 \\
\hline & Pediatric practice & 39 \\
\hline & Both adult and pediatric practice & 6 \\
\hline \multirow[t]{3}{*}{ Transition care provider } & No & 65 \\
\hline & Yes & 29 \\
\hline & Formerly & 7 \\
\hline \multirow{2}{*}{$\begin{array}{l}\text { Formal transition } \\
\text { care training }\end{array}$} & Specific to rheumatology & 22 \\
\hline & Not specific to rheumatology & 11 \\
\hline \multirow[t]{2}{*}{ Practice location } & Eastern Canada & 59 \\
\hline & Central and Western Canada & 41 \\
\hline \multirow[t]{2}{*}{ Practice setting } & Academic practice & 77 \\
\hline & Community practice & 23 \\
\hline \multirow{3}{*}{$\begin{array}{l}\text { No. rheumatologists in } \\
\text { practice setting }\end{array}$} & Solo practice & 14 \\
\hline & $2-4$ rheumatologists & 28 \\
\hline & $>5$ rheumatologists & 57 \\
\hline \multirow[t]{3}{*}{ Age, yrs } & $<40$ & 31 \\
\hline & $40-60$ & 45 \\
\hline & $>60$ & 25 \\
\hline Sex & Female & 75 \\
\hline \multirow[t]{4}{*}{ Yrs in rheumatology practice } & $<5$ & 25 \\
\hline & $5-10$ & 23 \\
\hline & $11-15$ & 11 \\
\hline & $>15$ & 42 \\
\hline \multicolumn{2}{|c|}{ Medical school training in Canada } & 82 \\
\hline \multicolumn{3}{|c|}{ Internal medicine or pediatrics } \\
\hline \multicolumn{2}{|c|}{ residency training in Canada } & 86 \\
\hline \multicolumn{2}{|c|}{ Rheumatology training in Canada } & 92 \\
\hline
\end{tabular}

a Percentage may not add to $100 \%$ due to rounding.

1.2 Transition care processes in Canada. Twenty-one of 59 respondents (35.5\%) strongly agreed or agreed that they were satisfied with the current transition processes in place, and only $23.7 \%$ strongly agreed or agreed they had sufficient resources and personnel to adequately address transition care. Twenty-four (38.7\%) of 62 respondents did not have a multidisciplinary transition service available in their area and $8(12.9 \%)$ of 62 respondents were uncertain if there was one. The majority of respondents did not have a designated staff member to coordinate transition ( $n=42 / 58,72.4 \%$ ), with responsibility assumed by physicians $(\mathrm{n}=10)$, a nurse $(\mathrm{n}=5)$, or an office administrator $(\mathrm{n}=1)$.

The timing of transfer was reported by the majority of respondents $(85.7 \%)$ to occur between the ages of $16-18$ years. Several factors beyond age were selected as important when informing the exact timing of transition, including increasing therapeutic options approved in adult but not pediatric rheumatology, patient readiness and request for transition, and disease activity. Life event transitions or logistical concerns such as physician workload or health insurance coverage were perceived as less important (Table 2).

The most important factors in choosing an adult rheumatology colleague to receive a transitioning patient was their expressed interest in transition and the quality of care provided (both responses selected as extremely/very important by $93 \%$ ).
The availability of specialized transition clinics, location of practice, feedback received from prior patients transitioning to the provider, provider's reputation in the community, and quality of communication were also frequently selected as extremely or very important (Supplementary Table 1, available from the authors on request). A clinical niche for the condition of the transferring patient was frequently cited in the free-text response box to this question.

When asked about the existence of transition policies in their practice, pediatric rheumatologists were more likely to have a written policy (32\% vs $3 \%$ of adult rheumatologists), and adult rheumatologists were more likely to respond that they had not given a written transition policy much thought $(32.4 \%$ vs $0 \%$ of pediatric rheumatologists; both $P=0.002$ ). Those without a formal transition policy did report following standard informal procedures $(52.9 \%$ adult, $60 \%$ pediatric rheumatologists). Having a transition policy did not vary by being engaged in a multidisciplinary transition care team $(P=0.27)$ or having had prior transition care training exposure $(P=0.22)$.

1.3 Major barriers to care. Availability of allied health providers to support transition (48.2\%), and the patient not being prepared for differences between pediatric and adult healthcare systems (48.2\%) were the most frequently identified barriers to care (Table 3). Other frequently cited barriers included availability of primary care to support transition (41.1\%), and concerns around parental adjustment to the adult system (39.3\%). Gaps in communication, coordination, guidelines, and protocols between the pediatric and adult systems were also identified concerns, as was coordination of care with other consulting specialty services. Insufficient time to address transition and lack of remuneration for transition care were identified by $37.3 \%$ and $44.8 \%$ of respondents, respectively. Together, barriers to transition and lack of transition clinic support to overcome these were perceived to present an advantage to remaining in pediatric care, related to the availability of resources and safety nets for patients, and the additional time available to support patient care.

1.4 Awareness of existing resources. Two-thirds of participants were aware of transition care resources $(n=43,66.2 \%)$, including those issued by the CAPHC $(n=12)$, CPS $(n=20)$, $\operatorname{AAP}(\mathrm{n}=8)$, EULAR/PReS $(\mathrm{n}=22)$, or a provincial $(\mathrm{n}=8)$, local hospital $(n=16)$, or online resource $(n=13)$. Pediatric rheumatologists were more frequently aware of existing practice resources $(P=0.002)$. Over half the respondents strongly agreed or agreed that additional tools were required to facilitate transition care ( $\mathrm{n}=33$ of 59 responses, 55.9\%). The identification of what additional resources are needed was informed by the respondents' level of comfort in addressing specific domains of transitional care (e.g., mental health, insurance and general health topics; Supplementary Table 2, available from the authors on request).

1.5 Perceived needs. Two-thirds of participants endorsed a need for a national approach to transition care $(\mathrm{n}=37$ of 56 responses, 66.1\%), and $16(28 \%)$ indicated they were not sure. Those who supported a national approach identified knowledge of processes of transition care and maintaining a compilation 
Table 2. Alternative suggestions to determine the timing of transition.

\begin{tabular}{|c|c|c|c|c|c|}
\hline Characteristics & Extremely Important & Very Important & Moderately Important & Slightly Important & Not at All Important \\
\hline Expanded therapeutic options & 40.0 & 38.3 & 11.7 & 6.7 & 3.3 \\
\hline Patient readiness & 38.3 & 43.3 & 18.3 & 0 & 0 \\
\hline Patient disease activity & 33.9 & 33.9 & 20.3 & 6.8 & 5.1 \\
\hline Age & 32.8 & 32.8 & 31.0 & 3.5 & 0 \\
\hline Parent request & 18.6 & 28.8 & 40.7 & 6.8 & 5.1 \\
\hline Marriage/family & 6.8 & 35.6 & 25.4 & 18.6 & 13.6 \\
\hline Graduating from college & 6.8 & 23.7 & 30.5 & 22.0 & 17.0 \\
\hline Transition to workforce & 5.2 & 32.8 & 34.5 & 17.2 & 10.3 \\
\hline Transition to college/postsecondary education & 5.2 & 31.0 & 36.2 & 15.5 & 12.1 \\
\hline Physician workload & 3.4 & 8.5 & 32.2 & 30.5 & 25.4 \\
\hline
\end{tabular}

Values are in $\%$.

Table 3. Major barriers to care ( $\mathrm{n}=56$ responses).

\begin{tabular}{lc}
\hline Major Barriers & $\begin{array}{c}\text { Proportion Indicating Factor Was a } \\
\text { Major Barrier to Care, \% }\end{array}$ \\
\hline Availability of allied health providers to support transition & 48.2 \\
Patient not prepared for differences between pediatric and adult healthcare systems & 48.2 \\
Availability of primary care to support transition & 41.1 \\
Parents having difficulty transferring responsibility to the youth & 39.3 \\
Patient/family expectations unrealistic of adult health system & 37.5 \\
Communication, coordination, guidelines, and protocols between pediatric & \\
and adult systems & 32.1 \\
Availability of practice resources/tools & 23.2 \\
Lack of knowledge of community supports & 21.4 \\
Lack of training in transition care & 19.6 \\
Patient knowledge/preparation about their disease and/or skills to self-advocate & \\
at physician visits & 19.6 \\
Adult rheumatologist's skills/knowledge & 17.9 \\
Inadequate communication of diagnosis, history, and/or treatment outcomes & 16.1 \\
Strong bonds existing with pediatric team & 16.1 \\
Lack of knowledge about disease course & 14.3 \\
Adult rheumatologist availability & 12.5 \\
\hline
\end{tabular}

transition resources in the local area as priorities to be addressed in this initiative (Table 4).

Phase 2: Models of rheumatology transition care in Canada 2.1 Participants. Nine interviews with 11 healthcare providers representing 9 transition clinics in British Columbia, Alberta, Ontario, Quebec, and Nova Scotia were completed; 1 additional interview was scheduled but not completed. Transition clinics would occur within academic hospital sites, with the exception of 2 sites where clinics were held outside the academic hospital setting. At the time of interview, transition care clinic structures had been in place for a range of 7 months to approximately 24 years at these sites, and had individual rosters varying between 25-300 active patients at any time.

2.2 Models and processes of transition care in Canadian clinics. Across clinics, 3 models of care were described: (1) direct transfer of care from pediatric to adult rheumatology providers; (2) a progressive model with overlap of pediatric and adult providers working toward assumption of responsibility of care by adult rheumatology providers; and (3) a shared care model between pediatric and adult rheumatology providers with set transition activities (Figure 1). In pediatric rheumatology, transition activities were introduced as early as age 13 in some clinics, with the majority initiating preparations closer to the patient's 18th birthday or graduation from high school. Transition activities encompassed empowering youth with knowledge about their conditions and treatments, gradually introducing and encouraging independence from parents for medical care, using specific transition tools to set goals and actions toward independence, and undergoing specific multidisciplinary assessments to identify ancillary supports needed prior to transfer to adult care. At 
Table 4. Focus for national transition activities ( $\mathrm{n}=52$ responses).

\begin{tabular}{lcc}
\hline Transition Activities & Extremely Important, \% & Very Important, \% \\
\hline Knowledge of process of transition care & 38.5 & 42.3 \\
Compendium of transition resources in my local area & 38.5 & 34.6 \\
Best practices in rheumatology transition care reference document & 35.3 & 39.2 \\
Knowledge of elements of transition care & 33.3 & 54.9 \\
Assessment of transition readiness & 32.7 & 46.2 \\
Guidelines for pharmacotherapy treatment for adults with & & 36.5 \\
$\quad$ juvenile-onset disease & 26.9 & 32.7 \\
Guidelines for nonpharmacotherapy treatments for adults with & & 42.3 \\
$\quad$ juvenile-onset disease & 25.0 & 32.7 \\
Care pathway for rheumatology transition care & 23.1 & 17.3 \\
Compendium of transition resources available at a national level & &
\end{tabular}

some sites using the direct transfer of care model, there were not any formalized transition activities prior to or following transfer. Seven of the sites had access to allied health providers during the transition process, including nursing, social work, physiotherapy, occupational therapy, child life specialists, pharmacy, psychology, nutrition, vocational training, and driving assessors; however, these teams were not widely available outside of pediatric-based clinic sites. Connecting patients to primary care was difficult in most provinces; this was related to patients and families being habituated to pediatric care teams, and to the lack of availability of physicians. As a result, primary care management frequently defaulted to the adult rheumatologist. The majority of sites did not have a patient/family advisory committee or written transition policy. Charting systems were distinct between pediatric and adult rheumatology sites (in all but one), which required duplication of historical data entry during transfer. Five sites had formalized tracking of patient outcomes, 4 sites collected patient experience information, and 7 sites were engaged in transition care-related research. Formalized education sessions on transition care topics were rare in the participating centres and thus knowledge and skill acquisition required providers to seek out these opportunities outside the institution; however, most transition clinics ensured pediatric and adult rheumatology trainees participated in the clinic to provide exposure to transition care.

2.3 Challenges and perceived needs. All participants indicated that the success of transition clinics hinged on allied health support; thus, funding for allied health providers outside of pediatric sites was seen as crucial for sustaining and expanding program resources. Programs and services to support youth in aspects outside of rheumatology clinical care, such as mental health resources and peer support groups, were difficult to access and felt to be critically important. Structural clinic issues including charting systems, scheduling and logistics supports, and communication methods accessible to youth were identified as needing to be resolved to support clinic efficiency and provide continuous care while improving follow-up visit rates. Practitioners in transition care cited limited time, large patient volumes, and lack of

\section{a) Direct Transition}

\section{b) Progressive Transition}
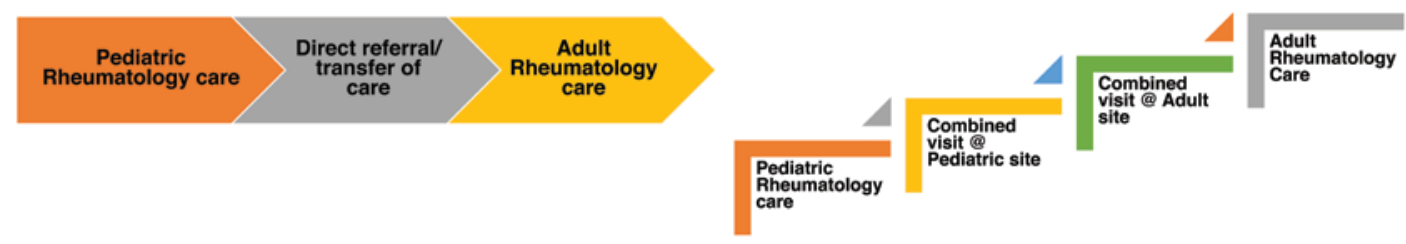

\section{c) Shared Care Transition}
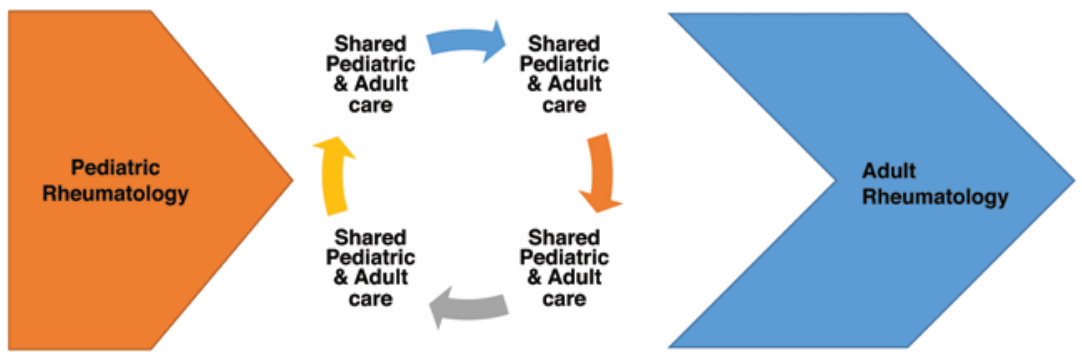

Figure 1. Models of care for transition of rheumatology patients from pediatric to adult care in Canada. 
recognition for the value of their work, either in their contracts (if salaried) or by fair remuneration (in fee for service settings), as barriers to care. Identified needs included the following: patient navigation methods; mechanisms to support parents and youth through the transition process, including establishing a network of transition providers across the country to facilitate patient relocation for school and employment; and funding of transition program evaluation to confirm the effect and quality of care provided in existing models, or tailoring where needed. Some sites were aiming to identify innovative ways to deliver care over large geographic areas.

Phase 3: Focus group and priority setting meeting

3.1 Participants. The session was attended by 26 participants either in person or online, representing adult $(\mathrm{n}=12)$ and pediatric $(n=8)$ rheumatologists, including providers specifically involved in transition care, patient representatives $(\mathrm{n}=3)$, and allied health professionals $(\mathrm{n}=3)$.

3.2 Prioritization results. Following the introductory presentation and results of the survey and environmental scan, a synthesized list of priorities was presented for consideration and voting (Figure 2). The priority receiving the highest number of votes was "supporting patient education for transition to adult rheumatology health care system" ( $\mathrm{n}=17)$, followed by "advocacy activities to access allied health support, including funding" $(\mathrm{n}=10)$. The next 3 priorities were tied: "Supports to implement existing guidelines/recommendations/best practices," "identify and promote models of care for transition that can be implemented in rural/remote locations," and "programs and services to support transition including mental health and peer support groups" ( $\mathrm{n}=8$ votes each). Discussion groups to identify potential activities and stakeholders for the top 2 priorities were held briefly, summarized in Supplementary Table 3 and Supplementary Table 4 (available from the authors on request).

\section{DISCUSSION}

This needs assessment and priority setting exercise provides direction to the Canadian rheumatology community to ensure youth with rheumatic diseases receive high-quality transition care. Although Canadian healthcare organizations have produced transition care resources (e.g., BC Children's Hospital Transition to Adult Care ${ }^{20}$, Alberta Health Services Well On Your Way ${ }^{21}$ ), youth with rheumatic diseases require specific attention, given the complexity of medical, psychosocial, educational, and vocational aspects unique to them. Despite international guidance ${ }^{10}$, even sites with established transition programs and expertise in transition care in Canada do not have the appropriate resources, supports, and educational opportunities to enact activities throughout the transition process to meet the standards. Enhanced education through training programs and continuing medical education venues should include content reflecting general transition and rheumatology-specific knowledge, tailoring developmental healthcare provision, and employing effective teaching strategies ${ }^{11}$. Our findings are consistent with an American survey highlighting lack of training in transition practices; insufficient resources, personnel, and time in clinic to adequately support the transition process; and the encountering of barriers in the coordination of transition care introduced by the complexity of rheumatologic conditions ${ }^{15}$.

The results support reconsideration of the timing of transfer. While some sites may transfer patients at various times based on readiness, for many, transfer is enforced by provincial health directives using age-based limits (i.e., age 18 yrs); this affects an optimal transition process with collaboration between pediatric and adult rheumatology teams as suggested in the EULAR/ PReS recommendations ${ }^{10}$. Canadian rheumatologists propose that clinical factors and disease activity, as well as patient factors including their readiness, level of independence, and self-management skills, be the guides for transfer instead.

What are the top 3 priorities to support high quality transition care?

\begin{tabular}{|c|c|c|c|c|c|}
\hline ADVOCACY & PRACTICE SUPPORTS & EDUCATION & NETWORKS OF SUPPORT & MODELS OF CARE & $\begin{array}{l}\text { RESEARCH and } \\
\text { EVALUATION }\end{array}$ \\
\hline $\begin{array}{l}\text { Advocacy activities to } \\
\text { access allied health } \\
\text { support, including } \\
\text { funding }\end{array}$ & Guidelines & $\begin{array}{l}\text { Supporting patient } \\
\text { education for transition } \\
\text { to adult rheumatology } \\
\text { health care system }\end{array}$ & $\begin{array}{l}\text { Support local } \\
\text { communities of practice } \\
\text { with pediatric and adult } \\
\text { rheumatology providers }\end{array}$ & $\begin{array}{l}\text { Identify and promote } \\
\text { models of care for } \\
\text { transition that can be } \\
\text { implemented in } \\
\text { rural/remote locations }\end{array}$ & $\begin{array}{l}\text { Funding and } \\
\text { infrastructure support to } \\
\text { evaluate the impact of } \\
\text { transition care initiatives }\end{array}$ \\
\hline $\begin{array}{l}\text { Advocacy activities to } \\
\text { access admin support, } \\
\text { including funding }\end{array}$ & Care pathways & $\begin{array}{l}\text { Offer training on } \\
\text { elements and processes } \\
\text { of transition care }\end{array}$ & $\begin{array}{l}\text { Support relationship } \\
\text { building with primary } \\
\text { care }\end{array}$ & $\begin{array}{l}\text { Navigation of health } \\
\text { system for complex } \\
\text { disease care plans }\end{array}$ & $\begin{array}{l}\text { Funding and } \\
\text { infrastructure support to } \\
\text { evaluate quality of care }\end{array}$ \\
\hline $\begin{array}{l}\text { Advocacy activities to } \\
\text { institute transition } \\
\text { teams, including funding }\end{array}$ & Best practices & $\begin{array}{l}\text { Offer training on medical } \\
\text { and psychosocial topics } \\
\text { related to transition }\end{array}$ & $\begin{array}{l}\text { Facilitate } \\
\text { interdisciplinary sharing } \\
\text { of knowledge and } \\
\text { learning between health } \\
\text { care professionals } \\
\text { nationally }\end{array}$ & $\begin{array}{l}\text { Programs and Services } \\
\text { to support transition } \\
\text { including mental health } \\
\text { and peer support groups }\end{array}$ & \\
\hline $\begin{array}{l}\text { Advocacy activities to } \\
\text { support access to } \\
\text { charting systems for } \\
\text { continuity }\end{array}$ & $\begin{array}{l}\text { Transition readiness } \\
\text { assessment tools }\end{array}$ & $\begin{array}{l}\text { Increasing interest in } \\
\text { rheumatology trainees } \\
\text { to provide transition } \\
\text { care }\end{array}$ & & $\begin{array}{l}\text { Compiling lists of } \\
\text { available local resources } \\
\text { to support transition }\end{array}$ & \\
\hline $\begin{array}{l}\text { Advocacy activities to } \\
\text { support access to } \\
\text { technology to support } \\
\text { communication with } \\
\text { patients }\end{array}$ & $\begin{array}{l}\text { Supports to implement } \\
\text { existing } \\
\text { guidelines/recommenda } \\
\text { tions/best practices }\end{array}$ & & & & \\
\hline
\end{tabular}

Figure 2. Voting grid. 
This activity has prompted collaboration between Canadian pediatric and adult rheumatology communities to identify priorities and establish the framework for a national transition initiative. The most pressing activity that emerged was to support patient and family education for transition to the adult rheumatology healthcare system. Working with partners and healthcare providers, dedicated national education sessions, and online peer-support services could be offered to patients and families. There was support to investigate the use of patient navigators in youth to adult rheumatology care transitions, as has been tested in youth with hemoglobinopathies ${ }^{22}$ and type 1 diabetes ${ }^{23}$.

Advocacy for access to funding to support allied health providers in transition teams and increasing interest in rheumatology nursing to support transition care teams is an urgent activity. Previously, one province lobbied for the introduction of billing codes that allowed for nursing support in outpatient rheumatology care $\mathrm{C}^{24}$ and this provides a roadmap for how support for transition care teams could be accessed. Supporting a mentoring program or offering virtual nursing support were of interest to national organization leadership. Canadian rheumatology leadership in advanced-skills practitioner training across allied health disciplines $^{25}$ serves as another model for action. The national organization is additionally directed to compile and facilitate interprovincial sharing of informational resources and disseminate previously developed practice recommendations, as well as to collaborate with mental health colleagues to identify access mechanisms for youth with rheumatic diseases. Activities led by the CRA's Access Subcommittee to provide distributed care across large geographic areas can be leveraged to develop appropriate transition care models for rural and remote populations.

We acknowledge limitations in this work. Rheumatologists who participated in the survey were mostly actively engaged or previously engaged in formalized transition care, and formed a relatively small sample of CRA members, despite nearly all pediatric and adult rheumatologists in Canada being required to participate in some form of transition care. In the interest of fidelity to existing survey tools and reducing time burden to participate in the survey, yet with enhanced interest and emerging research in transition care in rheumatology, the survey may not have included important dimensions on the content and mechanics of transition care. Participants in the interviews related their viewpoint of transition activities but may not have been aware of care activities provided by the receiving/transferring physicians, and a formal review of clinical resources and policies was not conducted. We facilitated both in-person and online participation in the focus group and priority setting meeting to ensure broad representation of care providers and patients, but it is possible that different priorities or viewpoints would have arisen with additional participation. This work did explicitly focus on transition care, rather than the specific care needs of emerging adults who develop a new rheumatic condition in late adolescence or early adulthood, have specific care needs without access to pediatric transition team resources, and are potentially affected by actions arising from this initiative.

In summary, Canadian youth with rheumatic diseases should be guaranteed access to high-quality and resourced transition care models, with strong collaboration between pediatric and adult rheumatology care providers, patients, families, and stakeholders.

\section{ACKNOWLEDGMENT}

Dr. Lori Tucker inspired this activity. We sincerely thank the Canadian Rheumatology Association for supporting this initiative through in-kind secretariat (Sue Ranta and Kevin Baljnauth) and meeting resources.

\section{REFERENCES}

1. American Academy of Pediatrics, American Academy of Family Physicians, American College of Physicians-American Society of Internal Medicine. A consensus statement on health care transitions for young adults with special health care needs. Pediatrics 2002; $6 \mathrm{Pt}$ 2:1304-6.

2. Lawson EF, Mellins ED. Paediatric rheumatic diseases: navigating the transition from paediatric to adult care. Nat Rev Rheumatol 2017;13:138-9.

3. McDonagh JE, Farre A. Transitional care in rheumatology: a review of the literature from the past 5 years. Curr Rheumatol Rep 2019;21:57.

4. Suris JC, Akre C. Key elements for, and indicators of, a successful transition: an international Delphi study. J Adolesc Health 2015;56:612-8.

5. Hazel E, Zhang X, Duffy CM, Campillo S. High rates of unsuccessful transfer to adult care among young adults with juvenile idiopathic arthritis. Pediatr Rheumatol Online J 2010;8:2.

6. Jensen PT, Karnes J, Jones K, Lehman A, Rennebohm R, Higgins $\mathrm{GC}$, et al. Quantitative evaluation of a pediatric rheumatology transition program. Pediatr Rheumatol Online J 2015;13:17.

7. van Pelt PA, Dolhain R, Kruize AA, Ammerlaan JJW, Hazes JW, Bijlsma JWJ, et al. Disease activity and dropout in young persons with juvenile idiopathic arthritis in transition of care: a longitudinal observational study. Clin Exp Rheumatol 2018;36:163-8.

8. Son MB, Sergeyenko Y, Guan H, Costenbader KH. Disease activity and transition outcomes in a childhood-onset systemic lupus erythematosus cohort. Lupus 2016;25:1431-9.

9. Felsenstein S, Reiff AO, Ramanathan A. Transition of care and health-related outcomes in pediatric-onset systemic lupus erythematosus. Arthritis Care Res 2015;67:1521-8.

10. Foster HE, Minden K, Clemente D, Leon L, McDonagh JE, Kamphuis S, et al. EULAR/PReS standards and recommendations for the transitional care of young people with juvenile-onset rheumatic diseases. Ann Rheum Dis 2017;76:639-46.

11. Sadun RE. Mind the gap: Improving care in pediatric-to-adult rheumatology transition through education. Rheum Dis Clin North Am 2020;46:103-18.

12. Chira P, Ronis T, Ardoin S, White P. Transitioning youth with rheumatic conditions: perspectives of pediatric rheumatology providers in the United States and Canada. J Rheumatol 2014; $41: 768-79$.

13. Barber CE, Jewett L, Badley EM, Lacaille D, Cividino A, Ahluwalia V, et al. Stand up and be counted: measuring and mapping the rheumatology workforce in Canada. J Rheumatol 2017;44:248-57.

14. Ravelli A, Sinigaglia L, Cimaz R, Alessio M, Breda L, Cattalini M, et al; Italian Paediatric Rheumatology Study Group and the Italian Society of Rheumatology. Transitional care of young people with juvenile idiopathic arthritis in Italy: results of a Delphi consensus survey. Clin Exp Rheumatol 2019;37:1084-91.

15. Zisman D, Samad A, Ardoin SP, Chira P, White P, Lavi I, et al. US adult rheumatologists' perspectives on the transition process for young adults with rheumatic conditions. Arthritis Care Res 2020;72:432-40 
16. Charlton P, Doucet S, Azar R, Nagel DA, Boulos L, Luke A, et al. The use of the environmental scan in health services delivery research: a scoping review protocol. BMJ Open 2019;9:e029805.

17. Graham P, Evitts T, Thomas-MacLean R. Environmental scans: how useful are they for primary care research? Can Fam Physician 2008;54:1022-3.

18. Canadian Paediatric Society. Transition to adult care for youth with special health care needs. Paediatr Child Health 2007;12:785-93.

19. Restall GJ, Carnochan TN, Roger KS, Sullivan TM, Etcheverry EJ, Roddy P. Collaborative priority setting for human immunodeficiency virus rehabilitation research: a case report. Can J Occup Ther 2016;83:7-13.

20. BC Children's Hospital. Transition to adult care. [Internet. Accessed December 9, 2020.] Available from: www.bcchildrens.ca/ our-services/support-services/transition-to-adult-care

21. Alberta Health Services. Well on your way. [Internet. Accessed December 9, 2020.] Available from: www.albertahealthservices.ca/ y2a/y2a.aspx
22. Allemang B, Allan K, Johnson C, Cheong M, Cheung P, Odame I, et al. Impact of a transition program with navigator on loss to follow-up, medication adherence, and appointment attendance in hemoglobinopathies. Pediatr Blood Cancer 2019;66:e27781.

23. Van Walleghem N, MacDonald CA, Dean HJ. Building connections for young adults with type 1 diabetes mellitus in Manitoba: feasibility and acceptability of a transition initiative. Chronic Dis Can 2006;27:130-4.

24. Connell J, Kur J, Gurmin JH. Assessing the impact of a nursing model of care on rheumatology practice patterns and patient satisfaction in British Columbia. BC Med J 2020;62:98-102.

25. Passalent LA, Kennedy C, Warmington K, Soever LJ, Lundon $\mathrm{K}$, Shupak R, et al. System integration and clinical utilization of the Advanced Clinician Practitioner in Arthritis Care (ACPAC) program-trained extended role practitioners in Ontario: a two-year, system-level evaluation. Health Policy 2013;8:56-70. 